\title{
Microstructure and Mechanical Properties of Mg-5Y-3Sm-0.8Ca Alloy
}

\author{
Qing Zhang, Quan-an Li, Jun Chen, Xing-yuan Zhang \\ School of Materials Science and Engineering \\ Henan University of Science and Technology \\ Luoyang, China \\ Collaborative Innovation Center of Nonferrous Metals, Henan Province \\ Luoyang, China \\ e-mail: foxzq@126.com
}

\begin{abstract}
Magnesium-RE alloys are interesting materials since they have excellent room and high temperature mechanical properties. A recently developed as-cast Mg-5Y3Sm-0.8Ca (wt.\%) alloy exhibits attractive strength at room temperature, while its strength is poor at elevated temperature. In order to further enhance its strength properties, solid solution and aging treatment is introduced. The microstructure and mechanical properties of $\mathrm{Mg}-5 \mathrm{Y}$ 3Sm-0.8Ca alloy have been investigated by means of microstucture observation and tensile tests. The results show that the microstructure of as-cast alloy consists of $\alpha-M g$ matrix, $\mathrm{Mg}_{24} \mathrm{Y}_{5}, \mathrm{Mg}_{41} \mathrm{Sm}_{5}$ and $\mathrm{Mg}_{2} \mathrm{Ca}$. After solid solution and aging treatment, the microstructure of the alloy is improved obviously. Meanwhile, the mechanical properties of the alloy are further enhanced and the alloy has high tensile strength at elevated temperature.
\end{abstract}

Keywords-magnesium alloy; rare earths; alloying; microstructure; mechanical properties

\section{INTRODUCTION}

As the lightest metallic structural materials and "the 21 st green engineering materials", Magnesium alloys have been widely used in the fields of automobile manufacturing and electronic industry due to their low density, high specific strength/stiffness, excellent damping effect and good recycling potential [1-4]. Magnesium-RE (rare earth elements) alloys are interesting materials since they have excellent room and high temperature mechanical properties [5-9]. It is believed that $\mathrm{Y}$ is the most effective rare earth element to improve the properties of magnesium alloys [10]. Sm is one of important rare earth elements, and has a high solubility in $\mathrm{Mg}$ among rare earth elements [11]. Recently, simultaneous addition of $\mathrm{Y}$ and $\mathrm{Sm}$ has been found to be significantly effective to increase the strength properties of magnesium alloys [12-17].

A recently developed as-cast $\mathrm{Mg}-5 \mathrm{Y}-3 \mathrm{Sm}-0.8 \mathrm{Ca}$ alloy exhibits attractive strength at room temperature [18], while its strength is poor at elevated temperature. In order to further enhance its strength properties, solid solution and aging treatment is introduced in this work. The microstructure and mechanical properties of $\mathrm{Mg}-5 \mathrm{Y}-3 \mathrm{Sm}-$ $0.8 \mathrm{Ca}$ alloy are investigated. It is hoped to provide a reference for the development of new type magnesium alloys.

\section{EXPERIMENTAL}

The compositions of tested Mg-Y-Sm-Ca alloy were designed as Mg-5Y-3Sm-0.8Ca (wt.\%). Pure metallic magnesium (99.95 wt.\%) and Mg-25 wt.\% Y, Mg-25 wt.\% $\mathrm{Sm}$ and $\mathrm{Mg}-25$ wt.\% Ca master alloys were used as raw materials. All the raw materials were baked at $200^{\circ} \mathrm{C}$ before the melting started.

The alloy was melted in an induction furnace with an $\mathrm{A} 12 \mathrm{O} 3$ crucible under the protection gas of 99 vol. $\% \mathrm{CO} 2$ and 1 vol.\% SF6. The melt was heated to $750^{\circ} \mathrm{C}$, and was poured into a metallic mold. The samples were cut from the casting and covered with $\mathrm{MgO}$ powder. Solid solution treatment was performed at $525^{\circ} \mathrm{C}$ for $6 \mathrm{~h}$, and then quenched in hot water. Aging treatment was made at $225^{\circ} \mathrm{C}$ for $12 \mathrm{~h}$, and then cooled in air.

The tensile tests were carried out at a strain rate of $1 \mathrm{~mm} / \mathrm{min}$ in an AG-I $250 \mathrm{kN}$ precision universal material test machine at room temperature $\left(25^{\circ} \mathrm{C}\right)$ and elevated temperature $\left(200^{\circ} \mathrm{C}\right)$.

The phase analysis was performed by D8 Advance Xray diffract meter (XRD). The microstructure observation was made by Olympus optical microscopy (OM). The strengthening phase and its compositions in the alloy were analyzed by JSM-5610LV scanning electron microscopy (SEM) and its energy dispersive spectroscopy (EDS).

\section{RESULTS}

\section{A. XRD pattern}

The XRD pattern of as-cast Mg-5Y-3Sm-0.8Ca alloy is shown in Fig. 1. The results show that its microstructure consists of $\alpha-\mathrm{Mg}$ matrix, $\mathrm{Mg}_{24} \mathrm{Y}_{5}, \mathrm{Mg}_{41} \mathrm{Sm}_{5}$ and $\mathrm{Mg}_{2} \mathrm{Ca}$. 


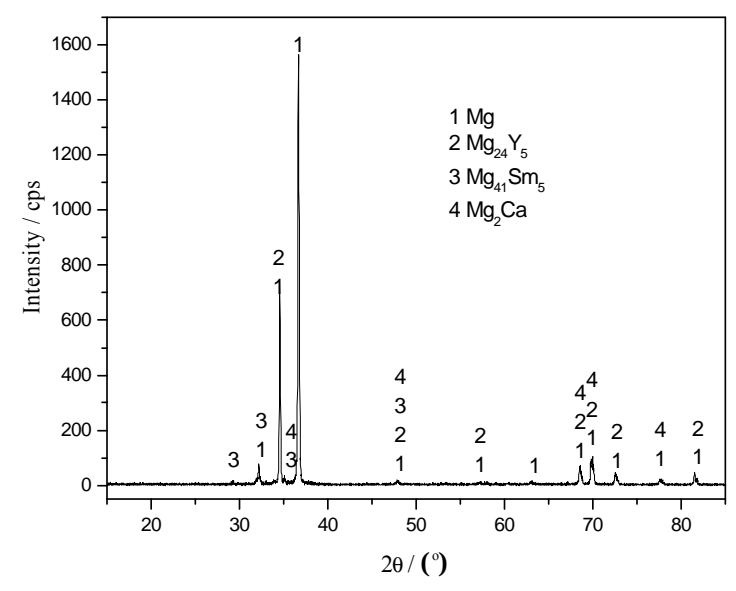

Figure 1. XRD pattern of as-cast Mg-5Y-3Sm-0.8Ca alloy

\section{B. Microstructure of as-cast alloy}

The microstructure of as-cast Mg-5Y-3Sm-0.8Ca alloy is shown in Fig. 2. It can be seen that the microstructure of the alloy consists of white matrix and grey precipitate phases. The white matrix should be $\alpha-\mathrm{Mg}$ and the grey precipitate phases should be $\mathrm{Mg}_{24} \mathrm{Y}_{5}, \mathrm{Mg}_{41} \mathrm{Sm}_{5}, \mathrm{Mg}_{2} \mathrm{Ca}$ or their mixture according to the XRD pattern in Fig. 1.

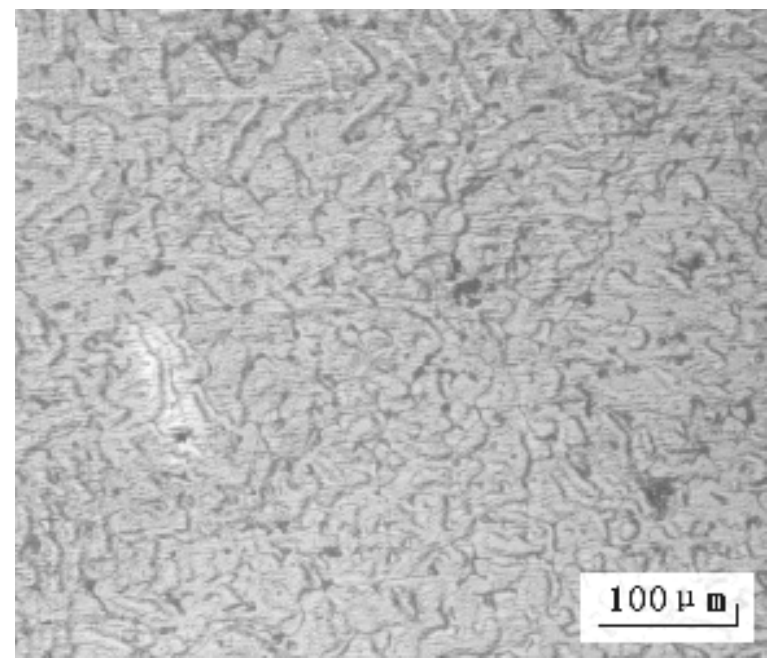

Figure 2. Microstructure of as-cast Mg-5Y-3Sm-0.8Ca alloy

\section{Microstructure of aged alloy}

The microstructure of Mg-5Y-3Sm-0.8Ca alloy after solid solution and aging treatment is shown in Fig. 3. It can be seen that the microstructure is not similar to that of ascast alloy shown in Fig. 2. The size of strengthening phase is finer, but the grain size has no obvious change. It can enhance the mechanical properties of the aged alloy.

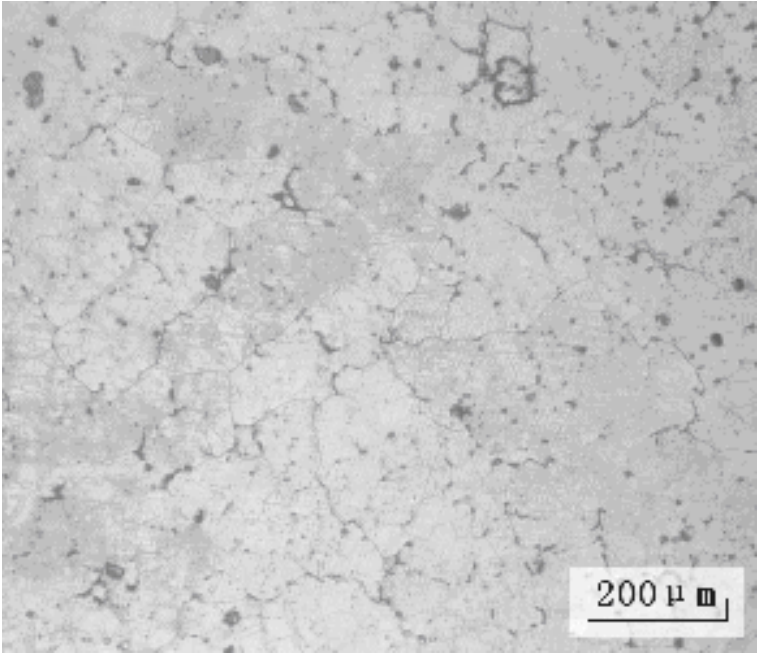

Figure 3. Microstructure of aged Mg-5Y $-3 \mathrm{Sm}-0.8 \mathrm{Ca}$ alloy

Fig. 4 and Fig. 5 show SEM imagine and EDS analysis results of strengthening phases in aged $\mathrm{Mg}-5 \mathrm{Y}-3 \mathrm{Sm}-0.8 \mathrm{Ca}$ alloy respectively. It can be seen that the strengthening phases in area A consist of four elements $\mathrm{Mg}, \mathrm{Y}, \mathrm{Sm}$ and $\mathrm{Ca}$. The content of $\mathrm{Y}$ and $\mathrm{Sm}$ is high, while the content of $\mathrm{Ca}$ is very low. Considering the XRD patterns in Fig. 1 together, there are $\alpha-\mathrm{Mg}$ matrix, $\mathrm{Mg}_{24} \mathrm{Y}_{5}, \mathrm{Mg}_{41} \mathrm{Sm}_{5}$ and $\mathrm{Mg}_{2} \mathrm{Ca}$ phases in the alloy and no other phases are formed. It can be drawn that the strengthening phase should be $\mathrm{Mg}_{24} \mathrm{Y}_{5}, \mathrm{Mg}_{41} \mathrm{Sm}_{5}, \mathrm{Mg}_{2} \mathrm{Ca}$ or their mixture.

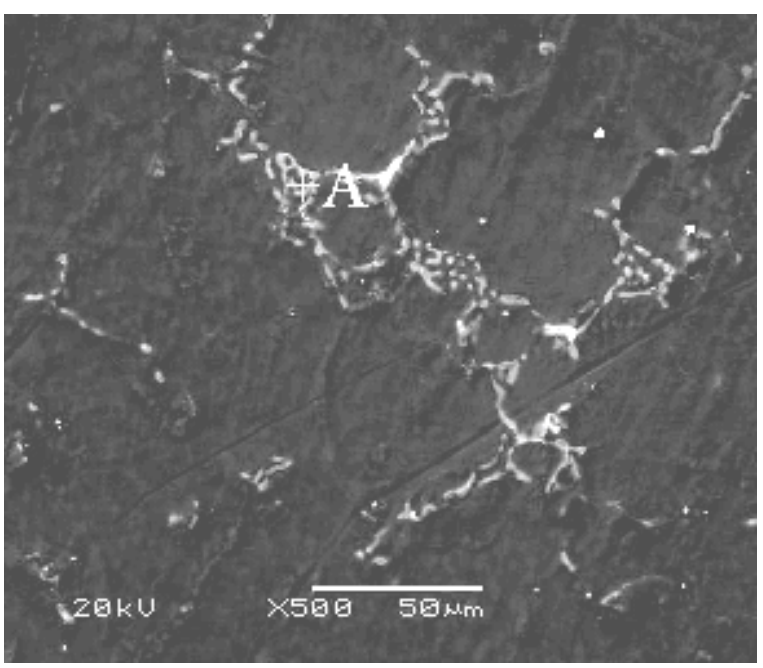

Figure 4. SEM imagine of aged Mg-5Y-3Sm-0.8Ca alloy 


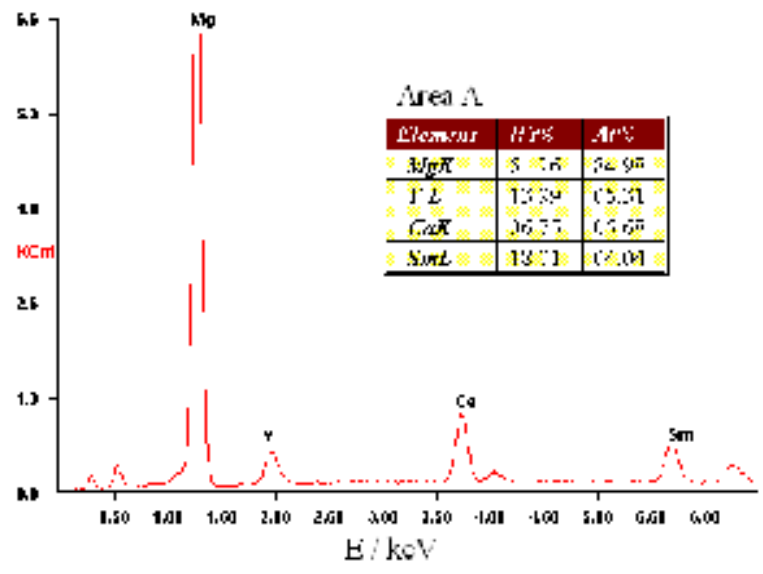

Figure 5. EDS results of marked area in Fig. 4

Based on the above results, the refinement effects of rare earth elements $\mathrm{Y}$ and Sm and alkaline earth element $\mathrm{Ca}$ on the grain of the alloy can be described as follows $[19,20]$ : (1) Part of them dissolves in $\alpha-\mathrm{Mg}$ matrix during the solidification of the alloy. It increases the number of homogeneous nucleation, and refines the grain size. (2) During the solidification of the alloy, high melting point compounds $\mathrm{Mg}_{24} \mathrm{Y}_{5}, \mathrm{Mg}_{41} \mathrm{Sm}_{5}$ and $\mathrm{Mg}_{2} \mathrm{Ca}$ act as a bar to the growth of $\alpha-\mathrm{Mg}$ grain, and lead to further refinement of the grain size of the alloy.

\section{Mechanical properties}

The mechanical properties of Mg-5Y-3Sm-0.8Ca alloy are shown in Table I. It can be seen that, at room temperature and $200^{\circ} \mathrm{C}$, the tensile strength of as-cast alloy is not very high, $208 \mathrm{MPa}$ and $182 \mathrm{MPa}$ respectively. After solid solution and aging treatment, the tensile strength of the alloy is increased to $224 \mathrm{MPa}$ and $206 \mathrm{MPa}$ respectively. Compared with that of as-cast alloy, the strength of aged alloy is enhanced by $16 \mathrm{MPa}$ at room temperature and $24 \mathrm{MPa}$ at $200^{\circ} \mathrm{C}$. It is consistent with the results of microstructure observation. It also can be seen that the change of elongation is not similar to that of the tensile strength. The elongation has no obvious change at room temperature and elevated temperature.

It follows that heat treatment plays an important role in strengthening Mg-5Y-3Sm-0.8Ca alloy. After suitable heat treatment, the strength property of $\mathrm{Mg}-5 \mathrm{Y}-3 \mathrm{Sm}-0.8 \mathrm{Ca}$ alloy can be improved obviously at room temperature and elevated temperature.

TABLE I. MECHANICAL PROPERTIES OF AGED ALLOY

\begin{tabular}{|l|c|c|c|c|}
\hline \multirow{2}{*}{$\begin{array}{c}\text { Alloy } \\
\text { state }\end{array}$} & \multicolumn{2}{|c|}{$\mathbf{2 5}^{\circ} \mathbf{C}$} & \multicolumn{2}{c|}{$\mathbf{2 0 0}^{\circ} \mathbf{C}$} \\
\cline { 2 - 5 } & $\begin{array}{c}\text { Tensile } \\
\text { strength } \\
{[\mathbf{M P a}]}\end{array}$ & $\begin{array}{c}\text { Elongation } \\
{[\%]}\end{array}$ & $\begin{array}{c}\text { Tensile } \\
\text { strength } \\
{[\mathbf{M P a}]}\end{array}$ & $\begin{array}{c}\text { Elongation } \\
{[\%]}\end{array}$ \\
\hline $\begin{array}{l}\text { as- } \\
\text { cast }\end{array}$ & 208 & 3.7 & 182 & 3.8 \\
\hline aged & 224 & 3.4 & 206 & 3.5 \\
\hline
\end{tabular}

\section{E. Strengthening mechanisms}

Aged Mg-5Y-3Sm-0.8Ca alloy has good strength properties, especially at elevated temperature. Considering the above results of microstructure analysis, one of the strengthening mechanisms in $\mathrm{Mg}-5 \mathrm{Y}-3 \mathrm{Sm}-0.8 \mathrm{Ca}$ alloy should be attributed to dispersion strengthening. High melting point phases $\mathrm{Mg}_{24} \mathrm{Y}_{5}, \mathrm{Mg}_{41} \mathrm{Sm}_{5}$ and $\mathrm{Mg}_{2} \mathrm{Ca}$ have high melting point and act as a bar to dislocation movement and boundary sliding. It causes the higher strength of the alloy at elevated temperature.

Of course, additional strengthening mechanisms, grain refinement strengthening and solid solution strengthening of alloying elements also play important roles in strengthening the alloy. All these strengthening mechanisms are connected with $\mathrm{Y}, \mathrm{Sm}$ and $\mathrm{Ca}$ addition. It proves again that $\mathrm{Y}, \mathrm{Sm}$ and $\mathrm{Ca}$ are effective alloying elements in strengthening magnesium alloys.

\section{CONCLUSIONS}

The microstructure of as-cast Mg-5Y-3Sm-0.8Ca alloy consists of $\alpha-\mathrm{Mg}$ matrix, $\mathrm{Mg}_{24} \mathrm{Y}_{5}, \mathrm{Mg}_{41} \mathrm{Sm}_{5}$ and $\mathrm{Mg}_{2} \mathrm{Ca}$. After solid solution and aging treatment, the microstructure of the alloy is improved obviously. Meanwhile, the mechanical properties of the alloy are further enhanced and the alloy has high tensile strength at elevated temperature.

\section{ACKNOWLEDGEMENT}

The financial support of the National Natural Science Foundation of China (NSFC-Henan Joint Fund of Personnel Training, No. U1404501), Innovative Research Team (in Science and Technology) in University of Henan Province (No. 2012IRTSTHN008), Basic and Frontier Technologies Research Plan of Henan Province (No. 092300410184) and Research Foundation of Henan University of Science and Technology (No. 2014QN013) is gratefully acknowledged.

\section{REFERENCES}

[1] Mordike B L, Ebert T. Magnesium: properties-applications-potential [J]. Materials Science and Engineering A, vol. 302, 2001, pp. 37-45.

[2] Luo A A. Recent magnesium alloy development for automotive powertrain applications [J]. Materials Science Forum, vol. 419-422, 2003, pp. 57-66.

[3] Chen Zhenhua, Chen Jihua. A review: Hot topics on magnesium technology in China [J]. Frontier Materials Science of China, vol. 2, 2008, pp. 1-8.

[4] Yan Jingli, Sun Yangshan, Xue Feng, et al. Creep deformation mechanism of magnesium- based alloys [J]. Journal of Materials Science, vol. 43, 2008, pp. 6952-6959.

[5] Mayumi Suzuki, Hiroyuki Sato, Kouich Maruyama, et al. Creep deformation behavior and dislocation substructures of $\mathrm{Mg}-\mathrm{Y}$ binary alloys [J]. Materials Science and Engineering A, vol. 319-321, 2001, pp. 751-755.

[6] Wang J G, Hstung L M, Nieh T G, et al. Creep of a heat treated Mg4Y-3RE alloy [J]. Materials Science and Engineering A, vol. 315, 2001, pp. 81-88,

[7] Rokhlin L L, Dobatkina T V, Tarytina I E, et al. Peculiarities of the phase relations in $\mathrm{Mg}$-rich alloys of the $\mathrm{Mg}-\mathrm{Nd}-\mathrm{Y}$ system [J]. Journal of Alloys and Compounds, vol. 367, 2004, pp. 17-19.

[8] LIU Xibo, CHEN Rongshi, HAN Enhou. High temperature deformations of $\mathrm{Mg}-\mathrm{Y}-\mathrm{Nd}$ alloys fabricated by different routes [J]. Materials Science and Engineering A, vol. 497, 2008, pp. 326-332.

[9] Lussana D, Massazza M, Riontino G. A DSC study of precipitation hardening in a WE43 Mg alloy [J]. Journal of Thermal Analysis and Calorimetry, vol. 92, 2008, pp. 223-225.

[10]Mayumi Suzuki, Tsuyoshi Kimura, Junichi Koike, et al. Effects of zinc on creep strength and deformation substructures in Mg-Y alloy [J]. Materials Science and Engineering A, vol. 387-389, 2004, pp. 706-709. 
[11]Kejie Li, Quanan Li, Xiaotian Jing, Jun Chen, Xingyuan Zhang, Qing Zhang. Effects of $\mathrm{Sm}$ addition on microstructure and mechanical properties of Mg-6Al-0.6Zn alloy [J]. Scripta Materialia, vol. 60, 2009, pp. 1101-1104.

[12]Li Daquan, Wang Qudong, Ding Wenjiang. Characterization of phases in $\mathrm{Mg}-4 \mathrm{Y}-4 \mathrm{Sm}-0.5 \mathrm{Zr}$ alloy processed by heat treatment [J]. Materials Science and Engineering A, vol. 428, 2006, pp. 295-300.

[13]Li Daquan, Wang Qudong, Ding Wenjiang. Effects of heat treatments on Microstructure and mechanical properties of $\mathrm{Mg}-4 \mathrm{Y}-$ 4Sm- $0.5 \mathrm{Zr}$ alloy [J]. Materials Science and Engineering A, vol. 448, 2007, pp.165-170.

[14]Li Daquan, Wang Qudong, Ding Wenjiang, et al. Influence of extrusion temperature on microstructure and mechanical properties of Mg-4Y-4Sm- $0.5 \mathrm{Zr}$ alloy [J]. Transactions of Nonferrous Metals Society of China, vol. 20, 2010, pp. 1311-1315.

[15]Li Quan-an, Zhang Qing, Wang Yaogui, et al. Effects of Sm addition on microstructure and mechanical properties of a Mg-10Y alloy [J]. China Foundry, vol. 11, 2014, pp. 28-32.
[16]Zhang Qing, Li Quan-an, Jing Xiaotian, et al. Microstructure and mechanical properties of Mg-10Y-2.5Sm alloy [J]. Journal of Rare Earths, vol. 28(Spec. Issue), 2010, pp. 375-377.

[17]Zhang Qing, Li Quan-an, Chen Jun, et al. Enhanced dispersion strengthening of $\mathrm{Sm}$ in $\mathrm{Mg}-10 \mathrm{Y}-0.5 \mathrm{Sm}$ alloy [J]. Advanced Materials Research, vol. 998-999, 2014, pp. 51-54.

[18]Zhang Qing, Li Quan-an, Chen Jun, et al. Microstructure and mechanical properties of $\mathrm{Mg}-\mathrm{Y}-\mathrm{Sm}-\mathrm{Ca}$ alloys [J]. Applied Mechanics and Materials, vol. 488, 2014, pp. 197-200.

[19]Bramfitt B L. Effect of carbide and nitride additions on the heterogeneous nucleation behavior of liquid iron [J]. Metallurgical and Materials Transactions B, vol. 1, 1970, pp. 1987-1995.

[20]Lee Y C, Dahle A K, Stjohn D H. The role of solute in grain refinement of magnesium [J]. Metallurgical and Materials Transactions A, vol. 31, 2000, pp. 2895-2906. 